\title{
GERAKAN SURYA NAMASKAR SEBAGAI METODE PENAPISAN DASAR ANAK USIA DINI
}

\author{
Oleh \\ ${ }^{1}$ Kadek Aria Prima Dewi PF \\ ${ }^{1}$ Fakultas Dharma Acarya Institut Hindu Dharma Negeri Denpasar \\ primadewipf@gmail.com
}

\begin{abstract}
Parents always want their children to grow into smart children, for that parents make various efforts to realize the desire, such as adding hours to learn children, also choose the best school according to parents. In fact, not all of these efforts have achieved maximum results, there are still children who experience slow learning, lack of fighting power, no discipline to run their daily activities, and so forth. It is important to obtain a child's readiness profile, one of which is by screening methods. In this research we will describe a screening method that takes one of the asanas yoga movements namely the namaskar solar movement. This movement involves aspects of basic observations in children, including balance, knee strength, and neck as an indicator of the form of motion control, emotion and communication of children.
\end{abstract}

Keywords: Yoga Asanas, Surya Namaskar, Screening, Early Childhood Education

\begin{abstract}
Abstrak
Orang tua senantiasa ingin agar anaknya tumbuh menjadi anak yang cerdas, untuk itu orangtua melakukan berbagai upaya untuk mewujudkan keinginan tersebut, seperti menambah jam belajar anak, juga memilihkan sekolah yang terbaik menurut orang tua. Faktanya tidak semua usaha tersebut memperoleh hasil yang maksimal, masih terdapat anak yang mengalami lambat belajar, kurang memiliki daya juang, tidak disiplin menjalankan aktivitas harian mereka, dan sebagainya. Penting sekali memperoleh profil kesiapan belajar anak, salah satunya dengan melakukan metode penapisan. Pada penelitian ini akan diuraikan sebuah metode penapisan yang mengambil salah satu gerakan yoga asanas yakni gerakan surya namaskar. Gerakan ini melibatkan aspek-aspek observasi mendasar pada anak, meliputi keseimbangan, kekuatan lutut, serta leher sebagai indicator bentuk kendali gerak, emosi dan komunikasi anak.
\end{abstract}

Kata Kunci: Yoga Asanas, Surya Namaskar, Penapisan, Pendidikan Anak Usia Dini

\section{PENDAHULUAN}

Usia dini merupakan masa kritis bagi perkembangan individu (Susilo \& Gabrielle, 2015: 1). Oleh karenanya diperlukan sebuah usaha yang lebih terencana yang dapat menyediakan lingkungan belajar yang kondusif untuk tumbuh kembangnya. Usaha tersebut dapat dilakukan dengan melakukan observasi atau pengamatan secara terstuktur tentang kesiapan anak dalam belajar. Kesiapan belajar anak masuk sekolah merupakan modal pertama untuk mengikuti proses kegiatan belajar di sekolah. Semakin besar kesiapan belajar yang dimiliki anak maka semakin besar anak memiliki kemampuan mengikuti poses kegiatan belajar di sekolah. Sebaliknya semakin kecil kesiapan belajar yang dimiliki anak maka semakin kecil 
anak memiliki kemampuan mengikuti poses kegiatan belajar di sekolah (Rifai \& Fahmi, 2017: 129).

Terkait dengan kesiapan sekolah, Hurlock (dalam Sulistiyaningsih, 2005) menyatakan bahwa kesiapan bersekolah terdiri dari kesiapan secara fisik dan psikologis, yang meliputi kesiapan emosi, sosial dan intelektual. Seorang anak dikatakan telah memiliki kesiapan fisik bila perkembangan motoriknya sudah matang, terutama koordinasi antara mata dengan tangan (visio-motorik) berkembang baik. Pada kenyataanya setiap orang tua selalu berkeinginan agar anaknya cerdas, sehingga dapat melalui masa-masa belajar dengan lancar. Banyak upaya dilakukan orang tua untuk mewujudkan keinginan itu, seperti dengan menambah jam belajar anak, dan memilihkan sekolah yang terbaik menurut orang tua. Tapi, terkadang hasilnya tak juga maksimal. Anak-anak masih lambat belajar, kurang daya juangnya, tidak disiplin menjalankan aktivitas harian mereka, dan banyak lagi masalah yang dijumpai dalam pendidikan anak.

William dan Schellenberger menunjukkan bahwa seorang anak tidak serta merta dapat berpikir dengan komprehensif tanpa melalui tahapantahapan tertentu yang berkaitan dengan perkembangan usia mereka. Dibutuhkan kematangan saraf secara bertahap yang akan menyiapkan struktur otak anak sehingga memiliki fungsi eksekutif yang sempurna. Priyanto (dalam Delviana, 2017: 125-126)) menguraikan beberapa kriteria kesiapan sekolah anak, yaitu: Pada perkembangan fisik : anak telah mampu berjalan di titian tanpa terjatuh, dapat memegang alat tulis dengan benar, mulai dapat memusatkan pandangannya pada benda-benda kecil dan mengkoordinasikan mata dan tangannya sehingga mampu melakukan aktivitas tertentu (mengancingkan baju sendiri, menyusun balok-balok, dllnya.) Pada perkembangan motorik halus : anak mampu membuat coretan-coretan yang lebih bermakna (orang, rumah, mobil, bunga, dllnya). Pada aspek kemandirian : ketergantungan pada orangtua atau orang dewasa lain mulai berkurang yang dapat terlihat dari mampunya anak untuk makan sendiri, sehabis main mampu membereskan mainan sendiri, mandi sendiri dllnya. Pada kemampuan konsentrasi : anak mampu memusatkan perhatiannya pada satu hal sehingga mampu tekun mengerjakan satu hal. Pada aspek sosial : anak mampu berbagi dan bermain bersama teman-temannya. Pada aspek kognitif : anak senang berbicara dan pertanyaan anak juga mulai rumit (tidak hanya menggunakan kata tanya "apa" namun sudah berkembang menjadi kata tanya "mengapa".

Untuk dapat mempersiapkan anak siap belajar dan bersekolah, maka salah satu kegiatan yang dapat dilakukan untuk memperoleh profil tersebut adalah dengan melakukan penapisan secara terstuktur sehingga kendala-kendala anak untu memasuki jenjang sekolah dapat segera di atasi. Dewasa ini kegiatan penapisan dilakukan dengan mengajak mengikuti kurang lebih 12 gerakan yang dapat menunjukkan titi-titik keseimbangan anak yang belum tercapai, juga bentuk 
kendali anak pada gerakan-gerakan dasar seperti merangkak, mendongak, tumpu dan sebagainya. Dalam proses penapisan tersebut, anak cenderung cepat merasa lelah karena demikian banyak gerakan yang harus dilakukan dan diulang. Sehingga data yang diperoleh senantiasa berubah-ubah, dan menyulitkan untuk melakukan penarikan kesimpulan. Untuk itu diperlukan sebuah metode baru dalam melakukan penapisan, yang tujuannya tetap mampu memberikan gambaran profil ana, namun jumlah gerakannya tidak terlalu banyak sehingga anak tidak cepat merasa lelah. Pada penelitian ini akan digambarkan metode penapisan dengan mengimplementasikan gerakan surya namaskar pada anak usia dini, untuk memperoleh profil kesiapan belajar anak yang komperhensif.

\section{PEMBAHASAN}

Penapisan adalah proses observasi terstruktur untuk mengamati perkembangan kerja otak melalui perkembangan kendali yang meliputi kendali gerak, emosi dan komunikasi (Pardamean \& Gracia, 2018: 1). Kegiatan penapisan dapat dilakukan oleh guru dengan syarat guru mampu membangun komunikasi dengan anak, mampu mengendalikan suasana serta memiliki kemampuan pengamatan indikator pada anggota tubuh.

Adapun hal-hal yang harus diperhatikan atau diamati dalam kegiatan penapisan adalah gerakan keseimbangan antara bagian kanan dan kiri tubuh anak, gerak sandi, gerakan mata, serta mimik wajah. Kegiatan penapisan ini menjadi penting dilakukan, mengingat kesiapan belajar anak dapat diihat dari bagaimana anak mampu mengendalikan otot-ototnya, yang nantinya akan berdampak kepada perkembangan kemampuan kognitif. Hal ini digambarkan secara rinci dalam piramida belajar William \& Shellenbeger.

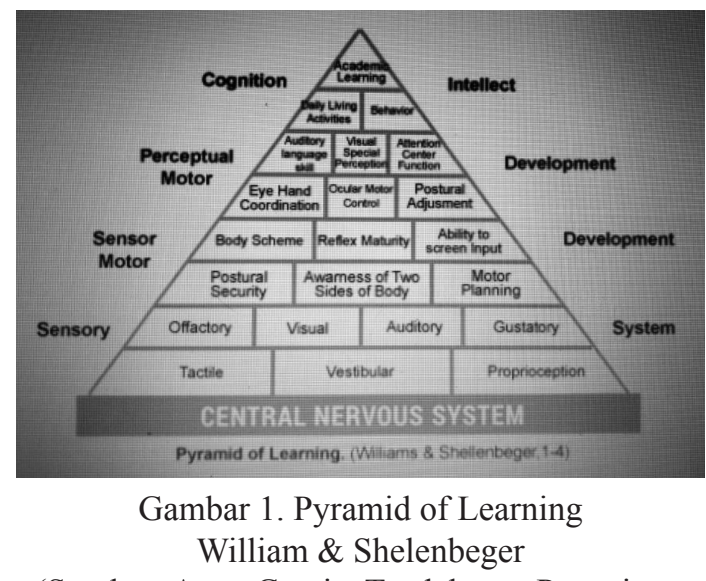

(Sumber: Anne Gracia Tatalaksana Penapisan, 2018)

Gambar ini menjelaskan bahwa seorang anak tidak serta merta dapat berpikir dengan komprehensif tanpa melalui tahapan-tahapan tertentu yang berkaitan dengan perkembangan usia mereka. Dibutuhkan kematangan saraf secara bertahap yang akan menyiapkan struktur otak anak sehingga memiliki fungsi eksekutif yang sempurna. Sistem sensori adalah bagian PERTAMA yang harus dibangkitkan dengan memberikan stimulasi agar dapat memasuki tahap KEDUA yang bertanggung jawab terhadap pengembangan sensori motor, tahap KETIGA di mana terdapat pengembangan perceptual motor, dan tahap KEEMPAT adalah kognitif/intelek.

Jika setiap tahap diberikan stimulasi yang tepat, maka target seorang anak memiliki daya pikir tingkat tinggi akan 
terwujud. Namun, karena keinginan instan sebagian besar orang dewasa, seringkali tahapan-tahapan tersebut terlewatkan, dimana stimulasi diberikan secara acak/ tak beraturan tanpa pemahaman tepat, mengakibatkan banyak bagian yang seharusnya disiapkan untuk mendukung fungsi eksekutif otak menjadi tidak siap. Tahapan kegiatan yang sesuai dengan piramida di atas, yaitu: 1) DC, PG, TK, SD: pada tahap ini kegiatan gerak berfungsi untuk membangun sistem sensor anak; 2) SD-SMP: pada tahap ini kegiatan gerak anak berfungsi untuk membangun sensory motor dan perceptual motor anak; 3) SMP-SMA: tahap kegiatan gerak anak berfungsi untuk membangun kognisi intelektual anak.

Pendidikan anak usia dini sebagai pendidikan pertama yang dilaksanakan secara terencana dan sistematis, idealnya memperhatikan aspek-aspek pemberian stimulasi yang tepat sesuai dengan tahap perkembangan. Faktanya masih banyak anak pada jenjang usia dini, belum mendapatkan stimulasi yang tepat sehingga dapat meghambat kesiapan belajar anak ke jenjang yang lebih tinggi. Untuk itu kegiatan penapisan penting untuk dilakukan, guna dapat memperoleh gambaran profil kesiapan belajar anak dan jenis stimulasi yang dapat diberikan sesuai dengan tahap perkembangannya.

Proses penapisan yang dilaksanakan dewasa ini meliputi observasi pada aktivitas jalan rapat, jalan silang, tumpu tunduk, berdiri dongak, berdiri tunduk, berdiri kanan kiri, tumpu 4 kanan, tumpu 4 kiri, tumpu dongak, tumpu tunduk, penapisan dengan observasi pada 11 (sebelas) gerakan tersebut di atas, memiliki kelemahan karena memerlukan banyak waktu karena cukup banyak gerakan yang harus dilakukan oleh anak, dengan berbagai jenis instruksi pada kemampuan anak yang beragam dan kelas yang cukup heterogen. Diperlukan sebuah gerakan penapisan, yang sederhana dengan satu instruksi dan dapat melibatkan otot dan persendian yang menjadi objek pengamatan.

Gerakan yang dapat dilakukan sebagai metode penapisan adalah salah satu gerakan yoga asanas yakni gerakan surya namaskara. Surya namaskara adalah sikap badan yang sangat penting dilakukan sebelum melakukan āsana yang berikutnya. Surya namaskara terdiri dari dua belas sikap badan, masing-masing berhubungan dengan salah satu dari dua belas lambang zodiak. Satu putaran yang lengkap dari Surya namaskara dua belas sikap badan yang dilakukan dua kali berturut-turut.

Gerakan surya namaskara memberikan sejumlah manfaat umum dan memiliki pengaruh yang sangat kuat pada semua jaringan tubuh seperti kelenjar endokrin, peredaran darah, pernafasan, pencernaan, dan juga untuk peningkatan konsentrasi. Dibawah ini dijelaskan kedua belas gerakan yang dimaksud.

\section{Pranamāsana (Sikap Berdoa)}

Berdiri tegak dengan kedua kaki dibuka satu kali lebar bahu. Kedua telapak tangan diletakkan secara bersamaan di depan dada. Kendorkan seluruh tubuh. Pandang lurus ke depan. 
Nafas:

Secara perlahan nafas dihembuskan.

\section{Manfaatnya:}

Membentuk suatu keadaan konsentrasi dan ketenangan dalam persiapan untuk melakukan latihan dan menghadapi alam semesta (Saraswati, 2002: 16).

Pada gerakan ini anak dikondisikan untuk berkonsetrasi, sehingga focus untuk mengikuti kegiatan penapisan dan dapat mengikuti instruksi yang diberikan oleh guru atau fasilitator.

\section{Hasta Uttanāsana (Sikap Kedua Lengan Terangkat)}

Angkat kedua lengan diatas kepala. Kedua lengan direnggangkan menurut lebar bahu masing-masing, kedua telapak tangan bisa disatukan atau dihadapkan keatas. Tekuk kepala dan tubuh bagian atas ke belakang, pandang sejauh mungkin ke belakang. Pinggul sedikit diangkat keatas.

Nafas:

Tarik nafas ketika mengangkat tangan keatas.

\section{Manfaat:}

Merenggangkan isi rongga perut, menghilangkan kelebihan lemak, dan memperbaiki pencernaan. Melatih otototot lengan dan bahu, menyelaraskan urat-urat syaraf, tulang belakang, dan membuka seluruh bilik paru-paru (Saraswati, 2002: 17).

Poin observasi atau indikator yang dapat diamati adalah badan bergoyang, kaki bergeser, postur dan mimik wajah.

\section{Pādahastāsana (Sikap tangan sampai kaki)}

Membungkuk ke depan sampai jarijari tangan atau kedua tangan menyentuh tanah pada tiap sisi atau di depan kedua kaki. Coba untuk mencium lutut. Kedua lutut tetap lurus tanpa ditekuk, dan konsentrasikan pandangan pada lutut.

Nafas:

Hembuskan nafas selama membungkuk kedepan.

\section{Manfaat:}

Dapat melenyapkan atau mencegah sakit perut dan juga berbagai penyakit perut lainnya. Mengurangi kelebihan lemak pada daerah perut, memperbaiki pencernaan, melancarkan peredaran darah. Membuat tulang belakang menjadi lemas (Saraswati, 2002: 18).

Poin observasi ada pada lengan bergerak dari axial tubuh searah gerakan kepala serta gangguan keseimbangan.

\section{4. Ásva Sancalanāsana (Sikap menunggang kuda)}

Letakkan kedua tangan pada kedua sisi kaki, tekuk lutut kaki kanan sambil melempar kaki yang sebelah kiri sejauh mungkin ke belakang. Jempol dan lutut kaki kiri menyentuh lantai, jari kaki kiri ditekuk. Panggul dicondongkan ke depan, lengkungkan tulang belakang dan menengadah. Tubuh dalam keadaan seimbang.

Nafas:

Tarik nafas ketika merentangkan kaki kiri ke belakang dan mendongak keatas. 
Manfaat:

Memijat organ-organ perut dan memperbaiki fungsinya. Otot-otot kaki akan diperkuat. Keseimbangan urat syaraf akan tercapai (Saraswati, 2002: 19).

Poin observasi atau ondikator yang dapat diamati adalah badan bergoyang, badan bertumpu pada telapak tangan, gerakan koordinatif antara kaki dan tangan, keseimbangan, kaki bergeser, postur dan mimik wajah.

\section{Parvatāsana (Sikap gunung)}

Kaki kanan diletakkan dibelakang dan berdampingan dengan kaki kiri. Perlahan angkat pantat keatas sedikit demi sedikit dan rendahkan posisi kepala dan letakkan diantara kedua lengan, sehingga tubuh membentuk segitiga dengan lantai. Letakkan tumit pada lantai pandangan diarahkan ke lutut lehernya dilipat kedalam.

Nafas:

Nafas dihembuskan selama meluruskan kaki dan membungkukan tubuh.

\section{Manfaat:}

Menguatkan syaraf dan otot-otot pada kedua lengan dan kaki. Melenturkan tulang belakang, pada arah yang berlawanan menuju sikap sebelumnya dan lebih jauh membantu membuatnya lemas. Menyelaraskan urat syaraf tulang belakang dan melancarka peredaran serta meningkatkan konsentrasi (Saraswati, 2005: 20).

Poin observasi atau indikator yang dapat diamati adalah badan bergoyang, badan bertumpu pada telapak tangan, serta telapak kaki, keseimbangan, kaki bergeser, postur dan mimik wajah.
6. Astāngga Namaskāra (Pemberi hormat dengan 8 anggota badan)

Tekuk lutut kelantai, letakkan dada dan dagu kelantai, pertahankan agar pantat tetap berada diatas. Kedua tangan, dagu, dada, lutut dan jari kaki menyentuh lantai serta tulang belakang dilengkungkan.

Nafas:

Nafas tetap dalam penghembusan seperti parvatāsana hanya pada tahap ini penarikan nafas dan penghembusan nafas berubah bergantian.

\section{Manfaat:}

Menguatkan otot kaki dan lengan serta memperkuat otot dada beserta perut (Saraswati, 2005: 21).

Poin observasi atau indikator yang dapat diamati adalah badan bertumpu pada telapak tangan, serta lutut, keseimbangan, postur dan mimik wajah.

\section{Bhujañgāsana (Sikap ular kobra)}

Rendahkan pinggul sementara mendorong dada kedepan dan keatas dengan bertumpu pada lengan, sampai tulang belakang melengkung kedua kaki dibelakang jangan dilipat atau diluruskan kedepan dan kepala didongakkan keatas.

Kaki dan perut bagian bawah tetap berada dilantai dan lengan menyokong tubuh.

Nafas:

Tarik nafas ketika mendongakkan kepala keatas dan membuka rongga dada ketika melengkungkan tulang belakang.

\section{Manfaat:}

Perut ditekan, membantu menekan darah yang berhenti dari organ-organ perut dan mendorong aliran darah 
segar. Sikap ini sangat bermanfaat bagi semua penyakit perut, termasuk ketidak mampuan mencerna dan sembelit. Melengkungkan punggung melatih tulang belakang, membuat otot-otot lemas dan meningkatkan konsentrasi (Saraswati, 2005: 22).

Poin observasi atau indikator yang dapat diamati adalah badan bertumpu pada telapak tangan, keseimbangan, postur dan mimik wajah.

\section{Parvatāsana (Sikap gunung)}

Posisi ini mengulang posisi 5. Pertahankan agar lengan dan lutut lurus. Sementara menggunakan bahu sebagai titik putar, angkat pantat dan turunkan kepala lipat lehernya, pandangan kelutut (Saraswati, 2002: 23).

Poin observasi atau indikator yang dapat diamati adalah badan bergoyang, badan bertumpu pada telapak tangan, serta telapak kaki, keseimbangan, kaki bergeser, postur dan mimik wajah.

\section{Asंva Sancalanāsana (Sikap menunggang kuda) \\ Posisi ini mengulang posisi 4 .} Tarik kaki kanan kedepan, dan letakkan kaki kanannya tepat ditengah-tengah kedua tangan. Secara perlahan letakkan lutut kiri kelantai dan dorong panggul kedepan. Lengkungkan tulang belakang dan pandang sejauh mungkin ke belakang (Saraswati, 2003: 24).

Poin observasi atau ondikator yang dapat diamati adalah badan bergoyang, badan bertumpu pada telapak tangan, gerakan koordinatif antara kaki dan tangan, keseimbangan, kaki bergeser, postur dan mimik wajah.

\section{Pādahastāsana (Sikap tangan sampai kaki)}

Posisi ini mengulang posisi 3 . Letakkan kaki kiri sejajar dengan kaki kanan dan luruskan, tekuk kedepan dan naikan pantat saat kepala diletakkan pada lutut. Kedua tangan tetap diletakkan disamping kaki (Saraswati, 2002: 25).

Poin observasi ada pada lengan bergerak dari axial tubuh searah gerakan kepala serta gangguan keseimbangan.

\section{Hasta Uttanāsana (Sikap kedua lengan terangkat) \\ Posisi ini mengulang posisi 2 .} Angkat atau jantaikan tangan diatas kepala. Kedua tangan bisa disatukan atau telapak tangannya dihadapkan keatas. Lengkungkan punggung dan angkat sedikit pinggulnya (Saraswati, 2002: 26).

Poin observasi atau indikator yang dapat diamati adalah badan bergoyang, kaki bergeser, postur dan mimik wajah.

\section{Pranamāsana (Sikap berdoa)}

Posisi ini mengulang posisi 1. Turunkan kedua tanggan dan cakupkan kedua tangan di depan dada (Saraswati, 2002: 27).

\section{PENUTUP}

Penapisan merupakan proses observasi terstuktur untuk mengamati perkembangan kendali gerak, emosi dan komunikasi untuk mendapatkan profil kesiapan belajar anak dan dapat mecapai kemampuan berpikir yang kritis. Kegiatan penapisan penting dilakukan karena anak pada usia dini menerima stimulus yang beraga, sehingga kemampuan dan 
kesiapan belajar masing-masing anak berbeda-beda. Kegiatan penapisan yang biasanya dilakukan dilakukan secara parsial, yang menyebabkan anak cepat kelelahan dan tidak mampu menerima instruksi, sehingga diperlukan metode yang lebih singkat dan kompleks. Gerakan surya namaskar merupakan salah satu gerakan yoga yang terdiri atas 6 gerakan inti, yang dilaksanakan secara berulang selama dua periode. Gerakan ini dapat memberikan data observasi yang lengkap untuk memperoleh profil kesiapan belajar anak mencapai kemampuan kognitif yang baik.

\section{DAFTAR PUSTAKA}

Delviana, Evi. (2017). Mempersiapkan Anak Masuk Sekolah Dasar dalam Jurnal JDP Volume 10, Nomor 2, Juli 2017.

Sulistiyaningsih, W. (2005). Kesiapan Bersekolah Anak Ditinjau Dari Jenis Pendidikan Pra Sekolah Anak dan Tingkat Pendidikan Orangtua. Jurnal Psikologia. Volume 01 - Juni 2005. Universitas Sumatera Utara.

Susilo,\& Yessica Diana Gabreila, 2015, Kesiapan Bersekolah Anak Taman Kanak kanak dan Komunikasi Ibu-Anak, Universitas Katolik Widya Mandala Surabaya http:// repository.wima.ac.id/7745/1/ Kesiapan\%20Bersekolah\%20 anak\%20TK\%20\%28Dicky\%20 $\% 26 \% 20$ Yessyca\%291.pdf tangal akses 23 Maret 2018.

Sarasvatī, Svāmī Satyānanda. 2002. Āsana Prañāyāma Mudrā Bandha. Surabaya: Pāramita.
Saraswatī, Svāmī Satya Prakās. 2005. Pātañjali Rāja Yoga (J.B.A.F. Mayor Polak Penerjemah). Surabaya: Parāmita.

Togu Pardamean \& Anne Gracia, 2018, Tata Laksana Kegiatan Penapisan, tp. 